\title{
Gebelik ve Tropikal Parazitik Enfeksiyonlar
}

\author{
Pregnancy and Tropical Parasitic Infections
}

\section{K. Emre KARAŞAHIN ${ }^{1}$, Mustafa ÖZTURK ${ }^{2}$, İbrahim ALANBAY ${ }^{1}$ Fahri Burçin FIRATLIGIL ${ }^{3}$}

1. TC SBÜ, Gülhane Eğitim Araştırma Hastanesi, Kadın Hastalıkları ve Doğum ABD, Ankara

2. TC SBÜ, Dr Sadi Konuk EAH, Kadın Hastalıklarl ve Doğum Servisi, Ankara

2. Hakkari Devlet Hastanesi, Kadın Hastalıkları ve Doğum Servisi, Hakkari

\section{ÖZET}

Parazit enfeksiyonları dünyada on milyon gebeyi etkilemektedir. Ülkemizde bölgelere göre değişmekle birlikte bu oranın \%20 civarında olduğu bildirilmektedir. Son dönemde ise Orta Doğu'daki çatışma ortamından kaçan göçmenler ile ülkemize bu oran artı̧̧ göstermektedir. Parazit enfeksiyonlarl maternal, fetal ve plasental seviyede etki eder. Maternal enfeksiyon yapan parazitler Ancylostoma duodenale, Necator americanus, Ascaris lumbricoides, Echinoccoccus granulosus; plasental enfeksiyon yapanlar Schistosoma mansoni, Schistosoma haematobium, Schistosoma japanicum, Plasmodium falciparum, Plasmodium vivax; fetal enfeksiyon yapanlar Leishmania chagasi, Leishmania donovani, Trypanosoma gambiense, Trypanosoma rhodesiense, Trypanosoma cruzi, Wuchereria bancrofti 'dir. Tanı metodları parazit türüne göre gaita, idrar, kan veya dokuda mikroskobik parazit incelemesi, serolojik test, polimeraz zincir reaksiyonudur. Bazl antihelmintik ilaçlar anne sütüne geçebilir. Antihelmintik ilaçların yanısıra oral demir destek tedavisi ya da cerrahi tedavi gerekebilir. Parazit enfeksiyonlarını engellemek için insektlerden vücudu koruyucu spesifik yöntemler, hijyenik besin ve su, kemoproflaksi kullanılır. Gebelikte parazit enfeksiyonları erken tanı ve uygun tedavi edilirlerse muhtemel kötü gebelik sonuçları önlenebilir.

Anahtar Kelimeler: gebe, parazitler, tropikal hastalıklar

\section{SUMMARY}

Parasitic infections influence ten of millions of pregnant worldwide. While the rate varies according to the regions in our country they are reported to be around $20 \%$. In recent years in our country, this rate is increasing by the migrants who escaped from the chaos in the Middle East countries. Parasitic infections show their effect at maternal, fetal and placental levels. Ancylostoma duodenale, Necator americanus, Ascaris lumbricoides, Echinoccoccus granulosus cause maternal infection, while Schistosoma mansoni, Schistosoma haematobium, Schistosoma japanicum, Plasmodium falciparum, Plasmodium vivax prefer to infect placenta and Leishmania chagasi, Leishmania donovani, Trypanosoma gambiense, Trypanosoma rhodesiense, Trypanosoma cruzi, Wuchereria bancrofti infect the fetus. The diagnostic methods are serologic testing, polymerase chain reaction and microscopic examination of parasites in the stool, urine, blood or tissues depending on the species. Some antihelmintic drugs can pass into breast milk. In addition to antihelmintic drugs oral iron supplements therapy or surgery may be required. Specific methods of insect body protector to prevent parasitic infections, you grant to pay attention to hygiene and water, chemoprophylaxis is used. To prevent parasitic infections, specific body insect protectors, hygienic food and water and chemoprophylaxis can be utilized. Possible poor pregnancy outcomes can be avoided with the early diagnosis and appropriate treatment of parasitic diseases.

Keywords: parasites, pregnant, tropical diseases
İletişim

Sorumlu Yazar: Fahri Burçin FIRATLIGiL, Kadın Hast. ve Doğ. Uzm.

Adres: Hakkari Devlet Hastanesi, Hakkari, Türkiye

Tel: +90 (438) 2116067

E-Posta: md.fahri@gmail.com

Makale Geliş: 10.01.2017

Makale Kabul: 11.11.2017

DOI: http://dx.doi.org/10.16948/zktipb.285199 *13'ncü Ulusal Jinekoloji ve Obstetrik Kongresi, Belek/An-
talya'da poster bildiri olarak sunulmuștur. 


\section{GíRiș}

Seyahat kolaylıkları ile birlikte ülkemizde uluslararası yolculuk sıklığı artmıştır. Gebelik sirasında tropikal bölgelere yolculuk yapacak olanların danışmanlığında özellikle parazit enfeksiyonlarına dikkat edilmesi gerekmektedir.

Parazit enfeksiyonları dünyada on milyon gebeyi etkilemektedir [1]. Kenya'da yapılan bir çalışmada gebelerin \%24'ünde kancalı kurt, $\% 17$ 'sinde ürogenital şistozoma, \%10'unda trişura, \%9'unda malarya saptanmıştır [2]. Ülkemizde bölgelere göre değișmekle birlikte bu oranın \%20 civarında olduğu bildirilmektedir [3]. Ancak tropikal ya da az gelişmiş ülkelere yapılan yolculuklar nedeniyle parazit enfeksiyonu olan gebe daha sık karşımıza çıkabilir. $\mathrm{Bu}$ nedenle paraziter hastalıkların, gebe ve fetusu nasıl etkilediğini bilmek önem taşımaktadır [4].

Hemen hemen tüm paraziter enfeksiyonlar anemi ve malnütrisyon yapar. Anemi ve malnütrisyon kötü gebelik sonuçlarıyla beraberdir [4]. Parazit ve tropikal enfeksiyonlar genellikle gebeleri, gebe olmayanlara göre daha fazla etkilemektedir. Fetal ve plasental etkiler ilk trimesterde gebeliğin sonraki dönemlerine göre daha ciddidir. İlk gebelikte parazitemi daha yoğun görülür. Gebelik sırasındaki immün sistem değişiklikleri parazit enfeksiyonlarına olan yatkınlığı artırır [1].

Parazit enfeksiyonları gebeliği maternal, fetal ve plasental seviyede etkiler. Parazit enfkesiyonlarını anneyi, fetusu ve plasentayı etkileyenler olarak sinıflandırabiliriz [4].

\section{Maternal enfeksiyon yapanlar:}

Ancylostoma Duodenale ve Necator Americanus: Kancalı kurtlar olup ya sindirim veya deriyi penetre ederek kan dolaşımına geçerler. İnce barsak mukozasında hasara yol açarlar. Hastada hipokromatik mikrositik anemi oluşur. Kancalı kurt enfeksiyonları düşük doğum ağırlıklı bebek ile ilişkili bulunmuştur. Gastrointestinal kan kaybı, malabsorbsiyon ve iştahsızlık demir, çinko ve protein-enerji eksikliğini ve gebelik anemisini arttırır [5].

Ascaris Lumbricoides: En s1k görülen helmint enfeksiyonlarından biridir. Yumurtalarının sindirim sistemine alınması ile başlar. Barsak, kan dolaşımı, akciğerler ve tekrar ince barsaklara ulaşarak evrimini tamamlar. Pankreatit, bilier obstrüksiyon ve intestinal obstrüksiyon gebelerde daha siktır. Koagulasyon patolojilerine yol açması nedeniyle postpartum hemorajilerde rolü olabilir [1].
Echinoccoccus granulosus: $\mathrm{Bu}$ parazit Kist Hidatik hastalığından sorumludur. Olağan konağı hayvanlar olup, insanlar tesadüfi konaktır. Enfekte canlının dışkısı ile dış ortama salınan parazit yumurtalarının gidaları kontamine etmesi sonucu bulaşır. Çoğunlukla karaciğerde olmakla birlikte akciğer, böbrek ve beyinde kist oluşur. Gebelikte bu kistlerin aşırı büyümesi ile çevre organlara bası etkisi oluşur. Terme yakın gebelerin kortikosteroid ve antihistaminikle kemoproflaksiye alınması gerekir. Doğum esnasinda kist rüptürü riski nedeniyle valsalva kontrendikedir. Elektif sezeryan ile doğum veya pasif ikinci evre doğum düşünülebilir [4].

\section{Plasental enfeksiyon yapanlar:}

Schistosoma mansoni, Schistosoma haematobium, Schistosoma japanicum: Larval formları cildi penetre ederler. Lenfatik kanal ve kapillerle akciğerlere, karaciğere migrasyondan sonra, intestinal kanaldaki veya mesane yak1nındaki büyük damarlara yerleşirler. Buralarda matür olduktan sonra yumurta salınımı başlar. Schistosoma endemik bölgelerdeki gebelerde sıktır [4]. Tubal granuloma neden olduğu için ektopik gebelik oluşabilir. Bu parazit plasentay1 geçerek fetusu da enfekte edebilir. Intrauterin gelişme geriliği, düşük doğum ağrılığ doğuma yol açabilir [1].

Plasmodium falciparum ve Plasmodium vivax: Gebelik sırasındaki malarya dünya çapında maternal morbidetenin önemli bir sebebidir. Kuzey Gana'da yapılan bir çalışmada gebelerin $\% 58$ 'inde Plasmodium türü saptanmıştır [6]. Bu infeksiyon sonucu 10.000 kadın ve 200.000 infantın öldüğü tahmin edilmekte olup, bu ölümlerin yarısindan fazlası ciddi maternal anemi, prematürite ve düşük doğum ağırlığından kaynaklanmaktadır. Çoğu infeksiyon P. falciparum veya $P$. vivax tarafindan oluşturulmaktadır.

Yoğun geçiş olan endemik bölgelerde maternal malarya insidans $1 \% 28$ olarak bildirilmektedir.

Düşük endemik bölgelerde ise oran \% 1.8-17.4 olarak saptanmıştır [7]. Malarya ilk gebelikte daha ciddi olmaktadır. Malaryanın komplikasyonları olan koma, renal yetmezlik, şok, DIC, serebrit ve ölüm gebelerde daha sık görülmektedir. Malaryal parazitler yüksek oranlarda plasentada birikmektedir ve sonucunda intervillöz aralıkta akümülasyon ile uteroplasental perfüzyon bozulmaktadir. Bunun sonucunda fetal gelişme geriliği, düşük doğum ağırlıklı bebek ve intrauterin ölüm gelişebilir. Malarya plasentayı geçerek fetusu da enfekte edebilir, bu durum neonatal sepsis veya intrauterin ölüm ile sonuçlanabilir [4]. 


\section{Fetal enfeksiyon yapanlar:}

Leishmania Chagasi ve Leishmania Donovani: Kala - Azar veya viseral leishmanisais kan kaynaklı protozoa olan L. chagasi ve L. donovani tarafindan oluşturulur. Viseral leishmaniyaziste kemik iliği ve dalak özellikle etkilenir. Plasentayı geçerek fetal hastalığa yol açarlar [4]. İnfantlar dissemine hastalık ile doğabilir. Tedavi edilmeyen hastalarda spontan gebelik kaybı görülebilir [1].

Trypanosoma gambiense, Trypanosoma rhodesiense, Trypanosoma cruzi: Kan kaynakl1 bir protozoadır. T. Gambiense ve, T. rhodesiense Afrika tripanosomiyazise, T. cruzei ise Chagas hastalığına yol açar. Maternal etkileri çok çalışılmamış olmasına karşın Chagas hastalığına bağlı kardiyomiyopati gebelikte ciddi sorunlara yol açar. Bu nedenle bu hastalığın endemik olduğu bölgelere gidenlere veya o bölgede yaşayanlara serolojk test yaptırmaları önerilir. Konjenital enfeksiyon gelişebilir [1].

Wuchereria bancrofti: Filariasis birçok arthropod geçişli nematodlardan kaynaklanmakla beraber, en sik etkeni Wuchereria bancrofti'dir. $\mathrm{Bu}$ enfeksiyon dünyada 120 milyon kişiden daha fazlasinı etkiler. Kronik fazda yumurtalar bacak ve pelvis damarlarına ilerler, ciddi lenf varisleri ve elefantiyazis oluşur [1].

Tanı için gaitada parazit yumurtası veya halkalarının araştırılması gerekir. Askariyaziste batın ultrasonografisi gerekebilir. Ayrica periferik kanda eozinofili, protrombin zamanı ve parsiyel tromboplastin zamanında uzama saptanabilir. Şistozomiyaziste gaita ve idrarda parazit yumurtası aranır. Laşmanyazis tanısında serolojik test kullanılır. Tripanozomiyaziste kan ve dokuda parazit aranır. Polimeraz zincir reaksiyonu veya serolojik testler de kullanılır. Filariyaziste kan ve doku örneklerinde mikroskobik olarak parazit aranır. Malarya ince ve kalın damla kan yaymasında taranır [1].

Bazı antihelmitik ilaçlar anne sütüne geçebilir. Emzirmeye ara vermek gerekebilir. Albendazol ve mebendazolün genellikle ilk trimestir d1şında kullanımının güvenli olduğu düşünülür. Dünya sağlık örgütü kancalı kurt enfeksiyon sıklığının \%20-30 olduğu bölgelerde proflaktik antihelmnitik tedavi ve oral demir destek tedavisi kullanımını önermektedir. Askariyaziste obstrüksiyon geliştiği takdirde cerrahi tedavi gerekebilir. Şistozomiyaziste praziquantel $20 \mathrm{mg} / \mathrm{kg}$ kullanılır. Laşmaniyazis tedavisinde beşli antimoniyal bileşikleri, meglumine antimonite kullanılır. Ancak bu ilaçlar gebelikte kontrendikedir.
Amfoterisin b gebelikte güvenli olarak kullanılabilir. Chagas hastalığında nifurtimoxor benzidazole kullanılır. Fakat bu ajanın gebelikte güvenilirliği ile ilgili net veri yoktur. Filiyaziste akut ve kronik enfeksiyon tedavisinde diethylcarbamazine ve albendazol güvenli bir şekilde gebelerde kullanılabilir [1]. Duyarlı ise klorokin ile malarya proflaksi tüm gebelikte güvenlidir. Dirençli etkenler için meflokin son iki trimesterde kullanılabilir. Primakuin gebelikte kontrendikedir [8].

Parazit enfeksiyonlarını engellemek için spesifik koruyucu yöntemlere ihtiyaç bulunmaktadır. En önemlileri insektlerden kaçınmadır. Dış ortam aktivitelerini azaltma, yatak tülleri kullanma, koruyucu giysiler giyme, yatak tülleri ve elbiselere permetrin uygulaması yapılabilir [4]. İnsektleri uzaklaştırmak için \% $\% 25^{\prime}$ den düşük konsantrasyonda diethyltoluamide cilde uygulanması gebelikte güvenlidir [8]. Diğer koruyucu yöntemler besin ve su hijyenine dikkat etmektir. Kancalı kurt enfeksiyonlarının önlenmesinde albendazol veya mebendazol kullanılır [1].

Gebelikte parazit enfeksiyonları erken tespit edilip ve uygun tedavi edilirlerse sonuçlar belirgin şekilde düzelir. Dünya çapında gebelikte parazit enfeksiyonlarının üzerinde durulması, özellikle yolculuk yapanlara dikkat edilmesi önem taşır.

\section{KAYNAKLAR}

1. Yakasai A, Umar UA. A review of parasitic infestation in pregnancy. Asian Journal of Natural \& Applied Sciences, Vol. 2. No. 1. March 2013.

2. McClure E, Meshnick SR, Mungai P, Malhotra I, King CL, Goldenberg RL et al. The association of parasitic infections in pregnancy and maternal and fetal anemia: a cohort study in Coastal Kenya. PLOS Neglected Tropical Diseases, Feb. 2014, Vol. 8, Is. 2.

3. Kara IH, Karaca M, Yayla M. Gebelik ve parazit enfeksiyonlart. Türk aile Hek Derg 1999, 3 (1-2):17-19.

4. Dotters-Katz S, Kuller J, Heine P. Parasitic infections in pregnancy. Obstet Gynecol Surv. 2011 Aug;66(8):51525 .

5. Steketee $R W$, Pregnancy, nutrition and parasitic diseases. The Journal of Nutrition, 1661-1667,2003.

6. Fuseini G, Edoh D, Kalifa BG, Hamid A-W, Knight $D$. Parasitic infections and anaemia during pregnancy in the Kassena-Nankana district of Northern Ghana. J. Public Health Epidemiol. Vol. 2(3), pp. 48-52, June 2010.

7. Desai M, ter Kuile FO, Nosten F, McGready R, Asamoa $K$, Brabin B, et al. Epidemiology and burden of malaria in pregnancy. Lancet Infect Dis. 2007;7(2): 93.

8. Cooper MC. The pregnant traveller. Travel Medicine and Infectious Disease 2006 (4), 196-201. 